\title{
Looking for a sepsis source
}

Damien Contou ${ }^{1,2^{*}}$ and Nicolas de Prost $^{2}$

Dear Editor,

We read with great interest the editorial written by de Waele and Sakr [1], in which the authors described their pragmatic strategy on how to search the source of a sepsis. It appears of paramount importance to precise that searching for a source of infection does not always mean finding a source of infection. Indeed, the lack of documentation (clinical or microbiological) of a source of infection during the 24 first hours of a septic shock is a common but disturbing and challenging clinical scenario reflected by the classical question "what does my patient have?" often heard during the morning rounds in many ICUs.

We recently reported in the Journal the results of a pragmatic multicenter prospective observational cohort study [2] including 508 patients admitted to the ICU for a suspicion of septic shock. It is worth notifying that more than a quarter of them $(n=134 / 506$, 26\%) had no source of infection nor microbiological documentation retrieved $24 \mathrm{~h}$ after shock onset (defined as the start of vasopressor infusion), despite an exhaustive diagnostic work-up. Indeed, these patients underwent more diagnostic testing with more imaging procedures-including computed tomography of the chest and abdomen and echocardiography-during the first $24 \mathrm{~h}$ of shock management, as compared to those with a source of infection identified within the first $24 \mathrm{~h}$ of shock. These patients without an "early confirmed septic shock" eventually had either a source of infection or a microbiological documentation retrieved after the 24 first hours $(n=37 / 134,28 \%)$-mostly a respiratory, urinary, or abdominal sepsis-or a sepsis mimicker $(n=59 / 134,44 \%)$ - mostly an adverse event of drugs, an acute mesenteric ischemia, or a malignancy-or a shock of unknown origin $(n=38 / 134$, 28\%). Mortality did not differ between patients with an early confirmed septic shock and those with a non early confirmed septic shock.

Intensivists should be aware that the absence of a source of infection is not so uncommon in the first $24 \mathrm{~h}$ of management of a patient with a suspected septic shock. A source of infection may be diagnosed later, but the hypothesis of a sepsis mimicker should be suspected in such a context.

\section{Authors' response}

Jan J. De Waele and Yasser Sakr

To the editor,

We agree with Drs. Contou and de Prost that in some patients with sepsis or septic shock, an infection diagnosis cannot be established in the first $24 \mathrm{~h}$. In their study on patients admitted to 10 ICUs in France, indeed a septic shock diagnosis could not be confirmed in $26 \%$ of patients [2]. In the majority of patients without confirmed septic shock, either no cause or another cause of the shock could be established, and only in less than 1 out

\footnotetext{
* Correspondence: damien.contou@ch-argenteuil.fr

This comment refers to the article available at https://doi.org/10.1186/ s13054-019-2675-3.

'Service de Réanimation Polyvalente, Centre Hospitalier Victor Dupouy, 69, rue du Lieutenant-Colonel Prud'hon, 95100 Argenteuil, France

${ }^{2}$ Service de Réanimation Médicale, Hôpital Henri Mondor, Assistance

Publique-Hôpitaux de Paris, 51 Avenue du Maréchal de Lattre de Tassigny,

94000 Créteil, France
} 
sepsis or septic shock was suspected in the emergency department, eventually no infection was documented [3]. Clearly this demonstrates that we remain poor at diagnosing sepsis-read diagnosing infection-and that we should acknowledge that in many patients in whom we suspect infection, in fact there is none. However, using a systematic approach, we should try to maximize the chances of establishing a final diagnosis of septic shock [1].

\section{Acknowledgements}

None.

\section{Authors' contributions}

DC and NDP wrote the letter. Both authors read and approved the final manuscript.

\section{Funding}

No funding.

Availability of data and materials

Not available.

Ethics approval and consent to participate

Not available.

\section{Consent for publication}

Not available.

\section{Competing interests}

The authors declare that they have no competing interests.

Received: 4 December 2019 Accepted: 17 December 2019

Published online: 14 January 2020

\section{References}

1. De Waele JJ, Sakr Y. How I search for a sepsis source. Crit Care. 2019;23:386.

2. Contou D, Roux D, Jochmans S, Coudroy R, Guérot E, Grimaldi D, et al. Septic shock with no diagnosis at 24 hours: a pragmatic multicenter prospective cohort study. Crit Care. 2016;20:360.

3. Klein Klouwenberg PM, Cremer OL, van Vught LA, Ong DS, Frencken JF, Schultz MJ, Bonten MJ, van der Poll T. Likelihood of infection in patients with presumed sepsis at the time of intensive care unit admission: a cohort study. Crit Care. 2015;19:319.

\section{Publisher's Note}

Springer Nature remains neutral with regard to jurisdictional claims in published maps and institutional affiliations. 